
Military Technical College
Kobry El-Kobbah, Cairo, Egypt.

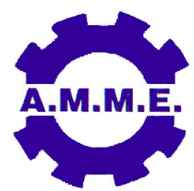
$16^{\text {th }}$ International Conference on Applied Mechanics and Mechanical Engineering.

\title{
DEVELOPMENT OF CFRE COMPOSITE JOINTS USING MWCNT/E ADHESIVES
}

\author{
U. A. Khashaba ${ }^{*}$, A. A. Aljinaidi ${ }^{*}$ and M. A. Hamed ${ }^{*}$
}

\begin{abstract}
Epocast 50-A1/946 epoxy was primarily developed for joining and repairing of composite aircraft structural components. The Epocast epoxy was modified by ultrasonic dispersion of Multi-Walled Carbon Nanotubes (MWCNTs) with different weight percentages. Neat epoxy (NE) and the optimum MWCNT weight percentage are used to fabricate structural adhesive joints (SAJs) with different scarf angles ( $5^{\circ}$, $10^{\circ}, 15^{\circ}, 30^{\circ}$, and $45^{\circ}$ ) in carbon fiber reinforced epoxy (CFRE) composite adherends. SAJs with different scarf angles were instrumented by eight strain gauges to measure the adherend tip strains and bond line strains during tension tests. The effect of water absorption on the tensile properties of the SAJs with $5^{\circ}$ and $10^{\circ}$ scarf angles was investigated experimentally. Because the SAJs with $5^{\circ}$ scarf angle have the highest tensile properties, special attention was considered to investigate their performance under elevated temperature $\left(50,75\right.$ and $\left.100^{\circ} \mathrm{C}\right)$ and fatigue loads. The tensile properties of the MWCNT/E-SAJs showed significant improvements compared to the neat epoxy-SAJs. Crack initiation and propagation were detected effectively using the instrumented-SAJs. The effect of water absorption has marginal effect on the tensile strengths of the SAJs. On the other hand, the tensile strengths and stiffness are dramatically decreased at elevated temperature. MWCNTs have insignificant effect on the fatigue lives of the SAJs.
\end{abstract}

\section{KEY WORDS}

Multi-Walled Carbon Nanotubes, Tension tests, losipescu in-plane shear tests, Structural adhesive joints, Carbon fiber composites, Scarf angles, Water absorption, Elevated temperature, Fatigue.

* Professors, Dept. of Mechanical Engineering, Faculty of Engineering, King Abdulaziz University, P.O. Box 80204, Jeddah 21589, Saudi Arabia.

+ On Leave from: Mechanical Design and Production Engineering Department, Faculty of Engineering, Zagazig University, P.O. Box 44519, Zagazig, Egypt. Corresponding author: Tel.: +966553507515; Fax: +96626952181.E-mails: khashabu@zu.edu.eg, khashabu@hotmail.com (U.A. Khashaba). 


\section{INTRODUCTION}

The weight and fuel savings offered by polymeric composite materials, due to their high specific strength and stiffness, makes them attractive not only to the military, but also to the civilian aircraft, space, and automobile industries. In these industries the adhesive joints are extensively used as a primary method of forming structural joints. Fatigue loads in these applications are usually unavoidable. Therefore, improving the adhesive properties in composite bonded joints will prolong the life of the product as well as ensure its safety, which is the main objective of the present work.

Recently, many researchers [1-13] have focused on the improving of epoxy materials using carbon nanotubes (CNTs). Some of them [12,13] used nanophased epoxy in adhesive joints/repairs.

Kwon [12] investigated the effect of infusion of different types and configurations (lengths and diameters) of multi-wall carbon nanotubes in epoxy matrix on the performance of the bonded scarf joints. Their results showed that CNTs provide enough enhancements in strength along the joint interface that is the weakest portion of the adhesive scarf joint.

Kang et al. [13] studied the static and fatigue strengths of adhesive single-lap joints incorporating carbon nanotubes to CFRE/aluminum adherends. They reported that the fatigue strengths and lives of the nanophased adhesive joints were increased compared to the control joint (without CNTs) and vice versa for the static strengths. Crack initiation and propagation were detected effectively by measuring the variation of equivalent resistance for the adhesive joints with nanophased epoxy.

Some investigators showed that the theoretical strength of bonded scarf joint specimens with small scarf angle $\left(2^{\circ}-3^{\circ}\right)$ have higher values compared to the larger scarf angles [14]. Experimentally, small scarf angle required extremely large repair lengths, which verified laminate failure predominantly by fiber fracture and pull-out $[14,15]$. Therefore, in the present work the minimum scarf angle will be taken $5^{\circ}$, which result in 57.15 repair length for $5 \mathrm{~mm}$ adherends thickness $\left(5 / \tan 5^{\circ}\right)$.

Many investigators studied the effect of bond line thickness on the strength of bonded joints/repairs [15-23]. Xiaoquan et al. [17] showed that when the adhesive film thickness is about $0.15-0.25 \mathrm{~mm}$, the ultimate stress of the scarf repaired plate reaches the highest value. Bond line thickness ranging from 0.2 to $0.25 \mathrm{~mm}$ is recommended by some researches $[15,19]$. Therefore, in the present work bond line thickness of $0.25 \mathrm{~mm}$ was adjusted for all the test samples. This value recommended for aircraft bonded composite joints [20,21].

The main objective of the present work is to improve the performance of bonded joints in composite structures through introducing nanofillers to the epoxy resin. Carbon fiber reinforced epoxy (CFRE) composite laminates were fabricated using prepreg technique. CFRE structural adhesive joints (SAJs) with different scarf angles $\left(5^{\circ}, 10^{\circ}, 15^{\circ}, 30^{\circ}\right.$, and $\left.45^{\circ}\right)$ and adhesive materials (neat epoxy and MWCNT/E) were locally fabricated. The tensile properties of the fabricated SAJs were determined at different environmental conditions and fatigue loads. 


\section{EXPERIMENTAL WORK}

\section{Materials}

The used epoxy is bisphenol A diglycidyl ether resin consists of two parts, which are epoxy part-A (Epocast 50-A1 resin) and epoxy part-B (Hardener 946) manufactured by Huntsman Advanced Materials Americas Inc. The epoxy system is an unfilled, solvent-free, easy-to-handle material for the manufacture and repair of composite structures as well as for filament winding. The mixing ratio is $100 \mathrm{~g}$ from epoxy partA: $15 \mathrm{~g}$ part from epoxy part-B. The viscosity of the epoxy system is $2,400 \mathrm{cP}$ at $25^{\circ} \mathrm{C}$.

The used Multi-Walled Carbon Nanotubes (MWCNTs) were manufactured by Timesnano, Chengdu Organic Chemicals Co. Ltd, Chinese Academy of Sciences. The outer diameter of MWCNTs is $<8 \mathrm{~nm}$ with $30 \mu \mathrm{m}$ length and the purity is $>95$ wt\%.

Carbon fiber reinforced epoxy (CFRE) composite laminates are fabricated using prepreg technique with 25 layer of T300-3k plain woven carbon fiber fabrics $\left(200 \mathrm{~g} / \mathrm{m}^{2}\right)$ and $\mathrm{YPH}-120-23 \mathrm{~A} / \mathrm{B}$ epoxy matrix. The laminate thickness is $5 \pm 0.1 \mathrm{~mm}$. The adherends were cut from CFRE laminates at different scarf angles $\left(5^{\circ}, 10^{\circ}, 15^{\circ}\right.$, $30^{\circ}$, and $45^{\circ}$ ).

\section{Optimum Weight Percentage of MWCNTs}

Four MWCNT/epoxy nanocomposite panels were fabricated using different weight percentages of MWCTs ranging from $0.25 \%$ to $1.0 \%$ with $0.25 \%$ increment. The MWCNTs are dispersed in epoxy resin using a high intensity Ultrasonic Processor (750 W), Cole-Parmer, Inc., USA. Four tension specimens cut from each panel and tested in accordance with ASTM D 638. Details about the sonication parameters, fabrication procedure of the nanocomposites, machining the standard tension test specimens, and characterization details are illustrated elsewhere, Khashaba et al. [10].

The experimental results showed that the MWCNT/E nanocomposite with $0.5 \mathrm{wt} \%$ MWCNTs has the highest improvements in the tensile properties compared to the other MWCNTs loading percentages. The in-plane shear properties of $0.5 \mathrm{wt} \%$ MWCNT/E nanocomposite was determined according to ASTM D5379 using losipescu test fixture and double V-notch specimens. Details about the test procedure are presented earlier, Khashaba et al. [10]. The experimental results showed that, compared to the neat epoxy, the improvement in the tensile strength and modulus of MWCNT/E nanocomposite are respectively $7.5 \%$ and $18.2 \%$, while the improvement in the shear strength and modulus are respectively $5.5 \%$ and $10.3 \%$.

\section{Characterizations of the CFRE Composite Adherends}

\section{Tension tests}

Tensile properties of the adherends were determined in accordance of ASTM D 3039. The dimensions of the test specimens are illustrated in Fig. 1. Five test 
specimens were cut into strips with $250 \mathrm{~mm}$ long and $25 \mathrm{~mm}$ width. Four rectangular aluminum end tabs were bonded to the griping length $(65 \mathrm{~mm})$ of three test specimens using a cold-hardening epoxy resin. These end tabs not only reduce the stress concentration from the serrated grips but also prevent the slipping of the test specimen from the grip, where the serration of the grip indented the aluminum tabs and engaged with it. End-tabs also smoothly transfer the lateral compressive load owing the grips of the testing machine to the specimen and prevent the crushing of the test specimens between the grips [24-26]. To measure the actual strains, modulus, and Poisson's ratio during the tensile test two samples were equipped with strain gages that bonded to the specimen back-to-back. The strain gages are connected to 4-channel data acquisition model $9237 \mathrm{NI}$, which connected to the PC to monitoring and recording the longitudinal and transverse strains during the tension tests.

\section{In-plane shear tests}

In-plane shear properties of CFRE composite adherends were determined in accordance with ASTM D5379 using losipescu test fixture and double V-notch specimens as shown respectively in Fig. $2 \mathrm{a}$ and Fig. $2 \mathrm{~b}$. The principle of the test is to apply a set of prescribed displacements on the V-notch specimen, so that the central region of the sample is under a state of predominant shear, Khashaba et al. [26]. These displacements are achieved through relative movement of the movable grip with respect to the fixed grip as shown in Fig. 2a.

To measure the shear strain $\left(\gamma_{x y}\right)$ and shear modulus $\left(G_{x y}\right)$ two strain gages were bonded at $+45^{\circ}$ and $-45^{\circ}$ at the center of the test specimen as shown in Fig. 2 . The strain gages are connected to the PC via 4-channel data acquisition model $9237 \mathrm{NI}$.

\section{Fabrication of the Structural Adhesive Joints}

\section{Preparation the scarf angles of the adherends}

The CFRE composite adherends $(500 \times 500 \mathrm{~mm})$ were cut to four panels each one has dimension equal $500 \times 125 \mathrm{~mm}$ using diamond bench saw [14]. To obtain adequate scarf profiles and surface roughness in the SAJs, the scarf angles $\left(5^{\circ}, 10^{\circ}\right.$, $15^{\circ}, 30^{\circ}, 45^{\circ}$ ) were grinded using a milling machine with 46 grit vitrified mounted points [15]. A metal back plate of $10 \mathrm{~mm}$ thickness was used as a support to prevent the laminate from bending excessively, during the scarf machining process [16]. Fig. 3 shows the machined adherend with $5^{\circ}$ scarf angle.

\section{Preparing the bonded surfaces}

To avoid contamination from loosely held debris after the machining process, the scarf surfaces of the adherends were cleaned by wiping them with acetonedampened cloth [14-17]. The cloth was dampening by pouring a small amount of solvent onto the cloth not by placing it in contact with the mouth of the bottle. To ensure drying of the mating sides of the scarf surfaces, the specimens are left $2 \mathrm{~h}$ in a clean, dust-free area with bonding surfaces upwards as recommended by $[14,16,17]$ and ASTM D 2093.

\section{Preparing the adhesive materials}

The predetermined optimum weight percentages of MWCNTs $(0.5 \mathrm{wt} \%)$ is dispersed in epoxy resin part-A using Ultrasonic Processor (750 W). Sonication parameters play a key role in dispersion of nanofillers in epoxy resin. These parameters include: 
beaker material and dimensions, cooling medium (air, water, water/ice), temperature control via probe, sonicator probe diameter, immersion depth of the sonicator probe, sonication power and amplitude, sonication time, sonication energy densities $(\mathrm{W} \cdot \mathrm{s} / \mathrm{ml})$, and sonication mode (pulse or continuous). The important of each parameter in the sonication process was reported by khashaba et al. $[10,11]$. The sonication parameters for dispersion of MWCNTs in epoxy resin are as follows:

- A cylindrical aluminum container with flat bottom and small diameter $(50 \mathrm{~mm})$ is used for dispersion $1.0436 \mathrm{~g}$ MWCNT in $150 \mathrm{~cm}^{3}$ of epoxy part-A. The mass of MWCNTs is calculated based on the total masses of epoxies part-A $(181.5 \mathrm{~g})$ and part-B (27.225g). The small diameter of high thermal conductivities aluminum container will maximize the mixture-probe surface area that exposed to the acoustic waves and accordingly, de-agglomerate the MWCNTs owing to the van der Waals attractive interactions.

- To reduce the damage of MWCNTs the sonication amplitude was $50 \%(375 \mathrm{~W})$ for $30 \mathrm{~min}$. Simple calculation showed that the energy densities during sonication of MWCNTs in $150 \mathrm{~cm}^{3}$ epoxy is $4500 \mathrm{~W} \cdot \mathrm{s} / \mathrm{ml}$.

- The maximum temperature of the mixture was kept lower than $50^{\circ} \mathrm{C}$ using temperature probe that fixed at about $1 \mathrm{~cm}$ away from the sonicator probe.

- Sonicator probe with $25 \mathrm{~mm}$ diameter was fixed for all the sonication processes.

- Sonication without cooling bath will raise the mixture temperature up to $50^{\circ} \mathrm{C}$ and accordingly, reduces the mixture viscosity that controls the dispersion of MWCNTs in epoxy resin.

- The sonicated mixture is put in a wide glass beaker to reduce its height and accordingly, increasing the mixture surface area. The beaker is then placed in drying vacuum oven model DZF-6050 at 133 vacuum pressure and $40^{\circ} \mathrm{C}$ for $1 \mathrm{~h}$. Heating the mixture up to $40^{\circ} \mathrm{C}$ under vacuum leads to decreasing its viscosity. Under such conditions, the included bubbles can be easily removed from the mixture.

\section{Fabrication procedures of the structural adhesive joint}

Bond line thickness was controlled using gage foil [22] with $0.25 \mathrm{~mm}$ thickness that fixed at the ends of the machined scarf surface of CFRE panel $(500 \times 125 \mathrm{~mm})$ as shown in Fig. 4. Because Epocast $50-\mathrm{A} 1 / 946$ has low gel time $\left(20 \mathrm{~min} 25^{\circ} \mathrm{C}\right)$, the heat can act as a catalyst and accordingly, reduce the gel time and speed up the curing process. Therefore, after evacuation the mixture (nanoparticles/epoxy part-A) is left to cool-down from $40^{\circ} \mathrm{C}$ up to the room temperature $\left(23^{\circ} \mathrm{C}\right)$. The hardener (epoxy part-B) was gradually added to the mixture (i.e. drop by drop), and manually stirred for $5 \mathrm{~min}$.

Adhesive layers were spread on the both mating scarf surfaces of the parent CFRE panels. The mating scarf surfaces of the panels were carefully placed on each other. The jointed panels $(500 \times 250 \mathrm{~mm})$ was compressed between two waxed glass plates using distributed dead weights of $50 \mathrm{~kg}$ to remove the excess adhesives and obtain joint planar. The bonded panels were held at room temperature $\left(23^{\circ} \pm 1 \mathrm{C}\right)$ for 10 days [22] to ensure complete curing of the epoxy. The bonded panels with different scarf angles were machined into tensile (static and fatigue) SAJs specimens with $250 \mathrm{~mm}$ length and $24 \mathrm{~mm}$ width, ASTM D3039. 


\section{Mechanical Characterizations of the SAJs}

\section{Tension testes of the SAJs}

The tensile properties of the SAJs were characterized using computer controlled universal testing machine model CMT5205/5305 MTS SYSTEMS. Fifty samples were tested to investigate the effects of scarf angle $\left(5^{\circ}, 10^{\circ}, 15^{\circ}, 30^{\circ}\right.$, and $\left.45^{\circ}\right)$ on the tensile properties of neat epoxy and MWCNT/E SAJs (five specimens for each scarf angles). Ten specimens were instrumented with eight strain gauges (one specimen for each scarf angle of the SAJs with different adhesive materials).

The adherend tip strains of the SAJs with $5^{\circ}$ scarf angle were measured through SG1, SG-2, SG-3, and SG-4. The strains of the long bond line of these specimens were measured through SG-5, SG-6, SG-7, and SG-8 as shown in Fig. 4a. The adherend tip strains of the SAJs with $10^{\circ}$ to $45^{\circ}$ scarf angles were measured through SG-1, SG-2, SG-3, SG-4, SG-5, and SG-6 while the bond-line-strains were measured through SG-7 and SG-8 as shown in Fig. 4b. The strain gauges were wired with coaxial cables to minimize the signal interference noise as shown in Fig. 4c. The tension tests are implemented at constant cross-head speed of $0.5 \mathrm{~mm} / \mathrm{min}[15,27]$.

\section{Tension testes of moist SAJs}

The effect of moisture absorption on the mechanical properties of the SAJs with $5^{\circ}$ and $10^{\circ}$ scarf angles was investigated experimentally. Gude et al. [28] showed that the saturation of epoxy and epoxy/CNT and epoxy CNF by water absorption is reached after about eleven days. Therefore, in the present work the specimens were immersed in distilled water up to about 22 days (526 h). The weight gain due to water absorption was measured using high sensitivity $(0.0001 \mathrm{gm})$ digital balance model A \& D HR-200. The tensile properties of the moist SAJs with different adhesive materials (neat epoxy and MWCNT/E) were determined according to ASTM D 3039. Six specimens were tested for each adhesive material (three for each scarf angle).

\section{Tension testes of the SAJs under elevated temperature}

Because, the SAJs with $5^{\circ}$ scarf angle has the maximum tensile properties compared with the other scarf angles, special attention will be given for studying their tensile properties under elevated temperature, and fatigue loads.

The effect of different temperature environments on the tensile properties of the SAJs with $5^{\circ}$ scarf angles was investigated using Instron universal testing machine model $8803(500 \mathrm{kN})$. The bond line strain was measured using Instron dynamic extensometer Model 2620-601 with $\pm 5 \mathrm{~mm}$ travel and 12.5/25/50 mm gauge lengths as shown in Fig. 5. The machine is provided by digital temperature chamber model Instron-3119-506 as shown in Fig. 5. The oven can perform temperature ranging from $-70^{\circ} \mathrm{C}$ to $+350^{\circ} \mathrm{C}$. Tension tests are implemented at three temperature levels ranging from $50^{\circ} \mathrm{C}$ to $100^{\circ} \mathrm{C}$ with $25^{\circ} \mathrm{C}$ increment. Nine test specimens with $5^{\circ}$ scarf angles were tested for each adhesive type (three specimens for each temperature level).

\section{Fatigue testes of the SAJs}

The SAJs were tested in tension-tension fatigue using an Instron servohydraulic universal testing machine model $8872(10 \mathrm{kN})$ at ambient laboratory environment. All 
the fatigue tests were performed under sinusoidal waveforms, constant load amplitude, frequency of $10 \mathrm{~Hz}$, and stress ratio of 0.1 [29-32]. The machine capacity $(10 \mathrm{kN})$ is very suitable for the fabricated specimens. The maximum load during fatigue tests was varied from $5 \mathrm{kN}$ to $7 \mathrm{kN}$, which approximately equal $35 \%$ to $50 \%$ of the average ultimate tensile loads in the joints. Before testing, the machine was auto tuned for the specimen stiffness as recommended by the Instron manual. The bond line strain under fatigue loads was measured using Instron dynamic extensometer Model 2620-604 with 12.5/-2.5 mm travel and 10/25/50 mm gauge lengths as shown in Fig. 6.

Thirty five SAJs with $5^{\circ}$ scarf angles were tested in fatigue (18 epoxy neat-SAJs and $17 \mathrm{MWCNT/E-SAJs).} \mathrm{At} \mathrm{least} \mathrm{three} \mathrm{stress} \mathrm{levels} \mathrm{were} \mathrm{tested} \mathrm{for} \mathrm{each} \mathrm{adhesive} \mathrm{type}$ to construct the S-N curve of the SAJs with $5^{\circ}$ scarf angles. The fatigue lives of the composites materials showed remarkable scatters even that the specimens are tested at the same conditions, Khashaba et al. [33,34]. Therefore, at least five specimens were tested for each stress level.

\section{RESULTS AND DISCUSSIONS}

\section{Tensile Properties of the Adherends}

The output of the universal testing machine PC is load (stress) vs time (displacement) curves. The output of 4-channel data acquisition model $9237 \mathrm{NI}$ is strain vs time. Therefore, to calculate the tensile modulus the stress-time and straintime relationships are drawn as shown in Fig. 7. The slopes of the tangent to the initial linear portion of these relationships were used to calculate the tensile modulus as shown in Fig. 7. Table 1 shows summary of the mechanical properties of the adhesives with maximum improvement in their tensile properties and CFRE composite adherends. It is interested to note that the value of Poisson's ratio, $v_{12}$, is equal to $0 / 90^{\circ}$ cross-ply CFRE composites (0.05) [35]. The lower value of Poisson's ratio of woven or cross-ply composites was due to the presence of fibers cross to the loading directions, which plays a key role in reducing the transverse strains under tensile loading and accordingly, decreasing the Poisson's ratio that equal the negative ratio of the strain in the transverse direction to the strain in the longitudinal direction as shown in Fig. 7.

Table 1. Mechanical properties of the used adhesives and adherends

\begin{tabular}{lccc}
\hline & \multicolumn{3}{c}{ Materials } \\
\cline { 2 - 4 } Properties & $\begin{array}{c}\text { Neat epoxy } \\
{[10]}\end{array}$ & $\begin{array}{c}0.5 \text { wt\% MWCNT/E } \\
{[10]}\end{array}$ & CFRE adherends \\
\hline Tensile modulus (GPa) & 3.43 & 4.06 & 81.66 \\
Shear modulus (GPa) & 1.45 & 1.60 & 6.94 \\
Poisson's ratio & 0.32 & 0.313 & 0.052 \\
Tensile strength (MPa) & 75.53 & 81.21 & 895.28 \\
Shear strength (MPa) & 50.71 & 53.51 & 145.41 \\
\hline
\end{tabular}


Figure 8 shows photographs of some fractured CFRE composites in tension. The figure showed that the tested specimens were completely fractured at the start of chamfering the aluminum tabs.

\section{In-Plane Shear Properties of the Adherends}

Fig. 9 shows load (shear stress)-displacement (time) curve of CFRE adherends. The specimen is not separated completely as in nanocomposite materials. The shear failure of the specimen was accompanied with evidently drop in the applied load after it reached the ultimate value. The load further rapidly increased due to the contact of the specimen at the lower right end of the V-notch with the fixed grip as shown in Fig. 10. In such case, the test should be stopped and the value of shear strength is calculated based on the ultimate shear load, Fig. 9, using the following equation:

$$
\tau_{x y}=\frac{P}{A}
$$

where $A$ is the cross-sectional area between the roots of two $\mathrm{V}$-notches, $\mathrm{P}$ is the ultimate load obtained from load-displacement curves of in-plane shear tests as shown in Fig. 9.

Figures 11-13 show the different stress and strain relationships of CFRE adherend from one losipescu shear test. These relationships are necessary to construct the shear stress $\left(\tau_{x y}\right)$ versus shear strain $\left(\gamma_{x y}\right)$ relationship, and accordingly to calculate the in-plane shear modulus as following:

The output of 4-Channels Data Acquisition Model $9237 \mathrm{NI}$ is strain versus time as shown in Fig. 11. This figure shows the strain-time relationship of $\pm 45^{\circ}$ strain gages. The output of the PC of universal testing machine is load-time (displacement) relationship. The load is divided by the cross-section area between the roots of two V-notches to obtain stress-time relationship as shown in Fig. 9. Linear curve fitting was performed to the first linear portion of the stress-time relationship as shown in Fig. 9. From the strain-time relationship of Fig. 11 and stress-time relationship of Fig. 9 the stress-strain relationship was constructed as shown in Fig. 12. The strain values in Fig. 12 are the output of $\pm 45^{\circ}$ strain gages, which converted to shear strain $\left(\gamma_{12}\right)$ using the following equation [36]:

$$
\gamma_{12}=\varepsilon_{-45}-\varepsilon_{+45}
$$

where $\varepsilon_{+45}$ and $\varepsilon_{-45}$ are the measured strains of the $+45^{\circ}$ and $-45^{\circ}$ strain gages respectively. Because the in-plane shears strain of $+45^{\circ}$ strain gage is negative and vice versa for $-45^{\circ}$ as shown in Fig. 12, the resultant shear strain is positive. Applying Eq. 2 to Fig. 12 the shear stress-shear strain relationship can be drawn as shown in Fig. 13. Thus, the in-plane shear modulus $\left(G_{x y}\right)$ is determined from the slope of the initial linear portion of shear stress-strain curve $\left(\Delta \tau_{x y} / \Delta \gamma_{x y}\right)$ as:

$$
G_{x y}=\frac{\Delta \tau_{x y}}{\Delta \gamma_{x y}}
$$


The average values of the in-plane shear strength and modulus of five tests are presented in Table 1. Most of the determined mechanical properties of the used adherends are closed to AGP370-5H/3501-6S woven carbon fiber composites prepared from prepreg by autoclave molding [37].

\section{The Tensile Properties of the SAJs}

\section{Bond-line-strains}

Figures 14 and 15 show respectively, the variation of bond-line-strain versus load of neat epoxy-SAJs and MWCNT/E- SAJs with different scarf angles. It can be seen from Figs. 14 and 15 that the bond-line-strains increase with increasing the scarf angles at the same load level. This behavior indicates that failure modes of the tested joints varied from shear in the bond materials at the smaller scarf angles (lower strains) to the interlaminar fracture between the adhesive/adherend interfaces (higher strains) for joints with large scarf angles. The results in Figs. 14 and 15 also showed that at the same bond-line-strain level the MWCNT/E-SAJs can sustain higher loads than neat epoxy-SAJs.

\section{Adherends-tip-strain}

Figures 16 and 17 show respectively the variation of adherends tip strains versus load of neat epoxy-SAJs and MWCNT/E-SAJs. The load-tip strains relationships shown in these figures have initial linear portion, which means that no damages detected. The slope of the load-tip strains curves was decreased due to the stress relief owing to crack initiation in the SAJs. The propagation of the cracks causes stress relaxation, which is translated into a sudden drop in the measured tip strains of SAJs as shown in Figs. 16 and 17. It can be seen from the figures that the adherends-tip-strains for specimens with $5^{\circ}, 10^{\circ}, 15^{\circ}$ scarf angles have higher strains compared to the adherends tip strains of $30^{\circ}$ and $45^{\circ}$ scarf angles and the adherend strain (from the tensile test of CFRE laminate) at the same load levels.

\section{Strength Properties of the SAJs}

Figure 20 shows the variation of ultimate tensile strength versus scarf angle of neat epoxy and MWCNT/E SAJs. It is evident from the figure that the ultimate tensile strength decreases with increasing the scarf angle. The results in Fig. 20 also showed that the tensile strengths of MWCNT/E-SAJs with different scarf angles are higher than that for neat epoxy-SAJs. Compared to neat epoxy-SAJs, the improvements in the tensile strengths of MWCNT/E-SAJs were $23.5 \%, 33.0 \%$, $22.0 \%, 12.0 \%$ and $40.0 \%$ for scarf angles of $5^{\circ}, 10^{\circ}, 15^{\circ}, 30^{\circ}$, and $45^{\circ}$ respectively. Fig. 21 showed that the fracture of the SAJs was accompanied with adhesive and adherend fractures.

Figures 18 and 19 show respectively the variations of ultimate failure tip and bond line strains versus scarf angle of neat epoxy and MWCNT/E SAJs. It is clear from the figures that the ultimate failure adherend tip strain was decreased with increasing scarf angle. In contrast, the ultimate failure of bond line strain increased with increasing the scarf angle. The results in Figs. 18 and 19 also showed that the ultimate failure strains of MWCNT/E-SAJs are lower that of neat epoxy-SAJs. These results indicate that the MWCNTs improve the SAJs stiffness. 


\section{Effect of Environmental Conditions}

\section{Effect of moisture absorption}

Figure 22 shows the variation of moisture content versus immersion time of neat epoxy and MWCNT/E SAJs with $5^{\circ}$ and $10^{\circ}$ scarf angles. Fig. 23 shows compression between the tensile strengths of dry and moist SAJs with $5^{\circ}$ and $10^{\circ}$ scarf angles. The results in this figures showed marginal decreases in the tensile strength of the moist joints compared to the dray one.

\section{Effect of temperature}

Figures 24 and 25 respectively show the load-displacement of neat epoxy and MWCNT/E SAJs tested at elevated temperatures. Figure 26 shows the effect of temperature on the strengths and compliances of the SAJs. It is clear from the figures that the SAJs have good and acceptable tensile strengths in the temperature range up to $50^{\circ} \mathrm{C}$, but their stiffness (inverse compliances) were dramatically decreased. The reduction in the ultimate tensile strengths were $2.3 \%, 77.5 \%$, and $90.9 \%$ for neat epoxy-SAJs tested respectively at $50^{\circ} \mathrm{C}, 75^{\circ} \mathrm{C}$ and $100^{\circ} \mathrm{C}$ compared to the tensile strength at room temperature $\left(23^{\circ} \mathrm{C}\right)$. Similarly, the ultimate tensile strengths of MWCNT/E-SAJs tested at $50^{\circ} \mathrm{C}, 75^{\circ} \mathrm{C}$ and $100^{\circ} \mathrm{C}$ were decreased by $15.6 \%, 83.1 \%$, and $92.8 \%$ respectively. Although the reductions in the ultimate tensile strengths of MWCNT/E-SAJs are higher than that of neat epoxy-SAJs, the ultimate tensile strengths of the former joints are higher than the latter one as shown in Fig. 26.

\section{Fatigue Behavior}

Figure 27 shows the experimental results of fatigue lives of the neat epoxy and MWCNT/E SAJs with $5^{\circ}$ scarf angles. The results in the figure showed that the infusion of MWCNTs in epoxy matrix has insignificant effect on the fatigue lives of the SAJs especially at high stress levels. The improvement in the fatigue stress at $10^{6}$ cycles is $2 \%$.

\section{CONCLUSIONS}

The present work shows modification of Epocast 50-A1/Hardener 946 epoxy resin by dispersion of $0.5 \mathrm{wt} \%$ MWCNTs using high intensity ultrasonic liquid processor. The sonication parameters are well quantitatively defined. Neat epoxy and MWCNT/E were used to fabricate structural adhesive joints (SAJs) with different scarf angles. The following concluding remarks can be drawn from this study:

1. Carbon fiber reinforced epoxy (CFRE) composite laminates are fabricated using prepreg technique with 25 layer of T300-3k plain woven carbon fiber fabrics $\left(200 \mathrm{~g} / \mathrm{m}^{2}\right)$ and $\mathrm{YPH}-120-23 \mathrm{~A} / \mathrm{B}$ epoxy matrix. The laminate thickness is $5 \pm 0.1$ $\mathrm{mm}$. Tensile and in-plane shear properties of the fabricated CFRE composites were characterized in accordance with ASTM D 3039 and ASTM D 5379 respectively. The determined mechanical properties are necessary for the finite element analysis that will be illustrated in the following papers.

2. The adherends were cut from CFRE laminates at different scarf angles $\left(5^{\circ}, 10^{\circ}\right.$, $15^{\circ}, 30^{\circ}$, and $45^{\circ}$ ). Neat epoxy and MWCNT/E SAJs with different scarf angles 
are fabricated and tested in tension. The experimental results showed that the ultimate tensile strength decreases with increasing the scarf angle. Compared to the neat epoxy-SAJs, the improvements in the tensile strengths of MWCNT/ESAJs were $23.5 \%, 33.0 \%, 22.0 \%, 12.0 \%$ and $40.0 \%$ for scarf angles of $5^{\circ}, 10^{\circ}$, $15^{\circ}, 30^{\circ}$, and $45^{\circ}$ respectively.

3. The adherend tip strains and bond line strains of the adhesive joints with different scarf angles and adhesive materials were measures using eight strain gauges for each specimen. The results showed that crack initiation and propagation can be effectively detected using the instrumented-SAJs. The results also showed that the ultimate failure adherend tip and bond line strains of MWCNT/E-SAJs with different scarf angles are lower than that of neat epoxySAJs. These results indicate that the MWCNTs improve the SAJs stiffness.

4. Because the SAJs with $5^{\circ}$ scarf angle have the highest tensile properties, special attention has been paid to investigate their performance under different environments and fatigue loads. The effect of moisture absorption on the mechanical behavior of the neat epoxy and MWCNT/E SAJs with $5^{\circ}$ and $10^{\circ}$ scarf angles was investigated experimentally. The SAJs specimens were immersed in distilled water up to about 22 days (526 h). The experimental results showed marginal decreases in the tensile strength of the moist joints compared to the dray one.

5. SAJs have good and acceptable tensile strengths in the temperature range up to $50^{\circ} \mathrm{C}$, but their stiffness (inverse compliances) are dramatically decreased. The reduction in the ultimate tensile strengths of the SAJs is more than $90 \%$ when tested at $100^{\circ} \mathrm{C}$. Although the reductions in the ultimate tensile strength of MWCNT/E-SAJs are higher than that of neat epoxy-SAJs, the ultimate tensile strengths of the former joints are higher than the latter one.

6. Fatigue behavior of the structural bonded joints with $5^{\circ}$ scarf angles and different adhesive materials (neat epoxy and MWCNT/E) was investigated using Instron servohydraulic universal testing machine model $8872(10 \mathrm{kN})$ under sinusoidal waveforms, constant load amplitude, frequency of $10 \mathrm{~Hz}$, and stress ratio of 0.1 . The fatigue results showed insignificant effect of MWCNTs on the fatigue lives of the SAJs especially at high stress levels. The improvement in the fatigue stress of MWCNT/E-SAJs at $10^{6}$ cycles is $2 \%$ compared to neat epoxy-SAJs.

\section{ACKNOWLEDGEMENTS}

This work was funded by King Abdulaziz City for Science and Technology (KACST), Riyadh, Saudi Arabia under grant DRP-5-3. The authors, therefore, gratefully appreciated to KACST for providing technical and financial support.

\section{REFERENCES}

1. Mujika F, Vargas G, Ibarretxe J, De Gracia J, Arrese A. Influence of the modification with MWCNT on the interlaminar fracture properties of long carbon fiber composites. Compos Part B-Eng 43, 1336-1340, (2012). 
2. Hossain MK, Hossain ME, Hosur MV, Jeelani S. Flexural and compression response of woven E-glass/polyester-CNF nanophased composites. Compos Part A-Appl S 42, 1774-1782, (2011).

3. Venkatanarayanan PS, Stanley AJ. Intermediate velocity bullet impact response of laminated glass fiber reinforced hybrid (HEP) resin carbon nano composite. Aerosp Sci Technol 21, 75-83, (2012).

4. $\quad$ Yang J-P, Chen Z-K, Feng Q-P, Deng Y-H, Li Y, Ni Q-Q, Yu S-Y. Cryogenic mechanical behaviors of carbon nanotube reinforced composites based on modified epoxy by poly(ethersulfone). Compos Part B-Eng 43, 22-26, (2012).

5. Loos MR, Yang J, Feke DL, Manas-Zloczower I. Effect of block-copolymer dispersants on properties of carbon nanotube/epoxy systems. Compos Sci Technol 72, 482-488, (2012).

6. Sallam, H.E.M., Khashaba, U.A. Seif, M.A., Abd-Elhamid, M. Megahed, A.A., Megahed, M.A., "Ultrasonic mixing of nanoparticles in epoxy resin", Int. Conf. on Nano-Technology for Green and Sustainable Construction 14-17 March, Cairo, Egypt, Edited by G. Yakovlev, Izhevsk Publishing House of ISTU, (2010).

7. Khan SU, Li CY, Siddiqui NA, Kim J-K. Vibration damping characteristics of carbon fiber-reinforced composites containing multi-walled carbon nanotubes. Compos Sci Technol 71, 1486-1494, (2011).

8. Jang J-S, Varischetti J, Lee G W, Suhr J. Experimental and analytical investigation of mechanical damping and CTE of both $\mathrm{SiO}_{2}$ particle and carbon nanofiber reinforced hybrid epoxy composites, Compos Part A-Appl S 42, 98103, (2011).

9. Uddin MF, Sun CT, Improved dispersion and mechanical properties of hybrid nanocomposites. Compos Sci Technol 70, 223-230, (2010).

10. Khashaba UA, Aljinaidi AA, Hamed MA. Nanofillers modification of Epocast 50A1/946 epoxy for bonded joints. Accepted for Publication, Chinese Journal of Aeronautics, (2014).

11. Alnefaie KA, Aldousari SA, Khashaba UA. New Development of Self-Damping MWCNT Composites. Composites: Part A 52, 1-11, (2013).

12. Kwon YW. Strength of Composite Scarf Joints. In: Brahim Attaf , Editor. Advances in Composite Materials - Ecodesign and Analysis, ISBN 978-953307-150-3, DOI: 10.5772/14320, InTech Open Access Publisher, Inc. 467-491, (2011).

13. Kang $\mathrm{M}-\mathrm{H}$, Choi $\mathrm{J}-\mathrm{H}$, Kweon $\mathrm{J}-\mathrm{H}$. Fatigue life evaluation and crack detection of the adhesive joint with carbon nanotubes. Composite Structures 108, 417-422, (2014).

14. Kumara SB, Sridhar I, Sivashanker S, Osiyemi SO, Bagc A. Tensile failure of adhesively bonded CFRP composite scarf joints. Materials Science and Engineering B 132, 113-120, (2006).

15. Campilho RDSG, de Moura MFSF, Pinto AMG, Morais JJL, Domingues JJMS. Modeling the tensile fracture behavior of CFRP scarf repairs. Composites: Part B 40, 149-157, (2009).

16. Kumar SB, Sivashanker S, Bag A, Sridhar I. Failure of aerospace composite scarf-joints subjected to uniaxial compression. Materials Science and Engineering A 412, 117-122, (2005).

17. Xiaoquan C, Baig Y, Renwei H, Yujian G, Jikui Z. Study of tensile failure mechanisms in scarf repaired CFRP laminates. International Journal of Adhesion \& Adhesives 41, 177-185, (2013). 
18. ASTM D 2093 - 03. Standard Practice for Preparation of Surfaces of Plastics Prior to Adhesive Bonding. Annual Book of ASTM Standards, Vol 08.01, (2003).

19. Adin $\mathrm{H}$. The effect of angle on the strain of scarf lap joints subjected to tensile loads. Applied Mathematical Modelling 36, 2858-2867, (2012).

20. Davies P, Sohier L, Cognard J-Y, Bourmaud A, Choqueuse D, Rinnert E, Cre' ac'hcadec R. Influence of adhesive bond line thickness on joint strength. International Journal of Adhesion \& Adhesives 29, 724-736, (2009).

21. Tomblin J, Yang C, Harter P. Investigation of Thick Bondline Adhesive Joints. DOT/FAA/AR-01/33, Federal Aviation Administration, National Technical Information Service, Springfield, AV, (2001).

22. Gacoin A, Lestriez $P$, Assih J, Objois A, Delmas Y. Comparison between experimental and numerical study of the adhesively bonded scarf joint and double scarf joint :Influence of internal singularity created by geometry of the double scarf joint on the damage evolution. International Journal of Adhesion \& Adhesives 29, 572-579, (2009).

23. Abdel Wahab MM, Ashcroftb IA, Crocombea AD, Smith PA. Finite element prediction of fatigue crack propagation lifetime in composite bonded joints. Composites: Part A 35, 213-222, (2004).

24. Khashaba, U.A., Aldousari, S.M., Najjar, I.M.R., "Behavior of $[0]_{8}$ Woven Composites under Combined Bending and Tension Loading: Part - I Experimental and Analytical", J. Composite Materials 46, 1345-1355, (2012).

25. Khashaba UA. Fracture behavior of woven composites containing various cracks geometry. J Compos Mater 37, 5-21, (2003).

26. Khashaba UA. In-plane shear properties of cross-ply laminates with different off-axis angles. J.Composite Structurs 65, 167-177, (2004).

27. Afendi M, Teramoto T, Bakri HB. Strength prediction of epoxy adhesively bonded scarfjoints of dissimilar adherends. International Journal of Adhesion \& Adhesives 31, 402-411, (2011).

28. Gude MR, Prolongo SG, Ureña A. Hygrothermal ageing of adhesive joints with nanoreinforced adhesives and different surface treatments of carbon fibre/epoxy substrates. International Journal of Adhesion \& Adhesives 40, 179187, (2013).

29. Fu M, Mallick PK. Fatigue of hybrid (adhesive/bolted) joints in SRIM composites. International Journal of Adhesion \& Adhesives 21, 145-159, (2001).

30. Zhang Y, Vassilopoulos AP, Keller T. Stiffness degradation and life prediction of adhesively-bonded joints for fiber reinforced polymer composites. J. Fatigue 30, 1813-1820, (2008).

31. Xiong JJ, Shenoi RA. Integrated experimental screening of bonded composites patch repair schemes to notched aluminum-alloy panels based on static and fatigue strength concepts. Composite Structures 83, 266-272, (2008).

32. Azari S, Jhin G, Papini M, Spelt J.K. Fatigue threshold and crack growth rate of adhesively bonded joints as a function of load/displacement ratio. Composites: Part A 57, 59-66, (2014).

33. Khashaba, U.A., Selmy, A.I., El-Sonbaty, I.A., and Megahed, M., "Behavior of notched and unnotched $\left[0 / \pm 30 / \pm 60 / 90_{\text {s }}\right.$ GFR/Epoxy Composites under static and fatigue loads" J. Composite Structures 81, 606-613, (2007).

34. Abd Allah, M.H., Abdin, E.M., Selmy, A.I., and Khashaba, U.A., "Reliability Analysis of GFRP Pultruded Composite Rods" J. Quality and Reliability Management, 13, 88-98, (1996). 
35. Corum JM, Battiste RL, Liu KC, Ruggles MB. Basic Properties of Reference Crossply Carbon-Fiber Composite. Oak Ridge National Laboratory, ORNL/TM2000/29, February (2000).

36. Khashaba UA, Sebaey TA, Mahmoud FF, Selmy AI, Hamouda RM, Experimental and numerical analysis of pinned-joints composite laminates: Effects of stacking sequences. J. Composite Materials 47, 3353-3366, (2013).

37. Abot JL, Yasmin A, Daniel IM. Hygroscopic Behavior of Woven Fabric CarbonEpoxy Composites. Journal of Reinforced Plastics and Composites 24, 195207, (2005).

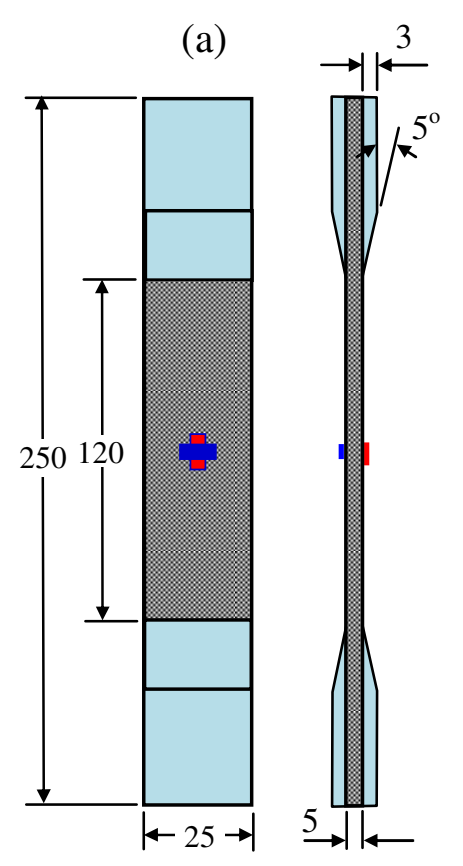

Fig. 1. Dimensions of tension CFRE specimen, ASTM D 3039.

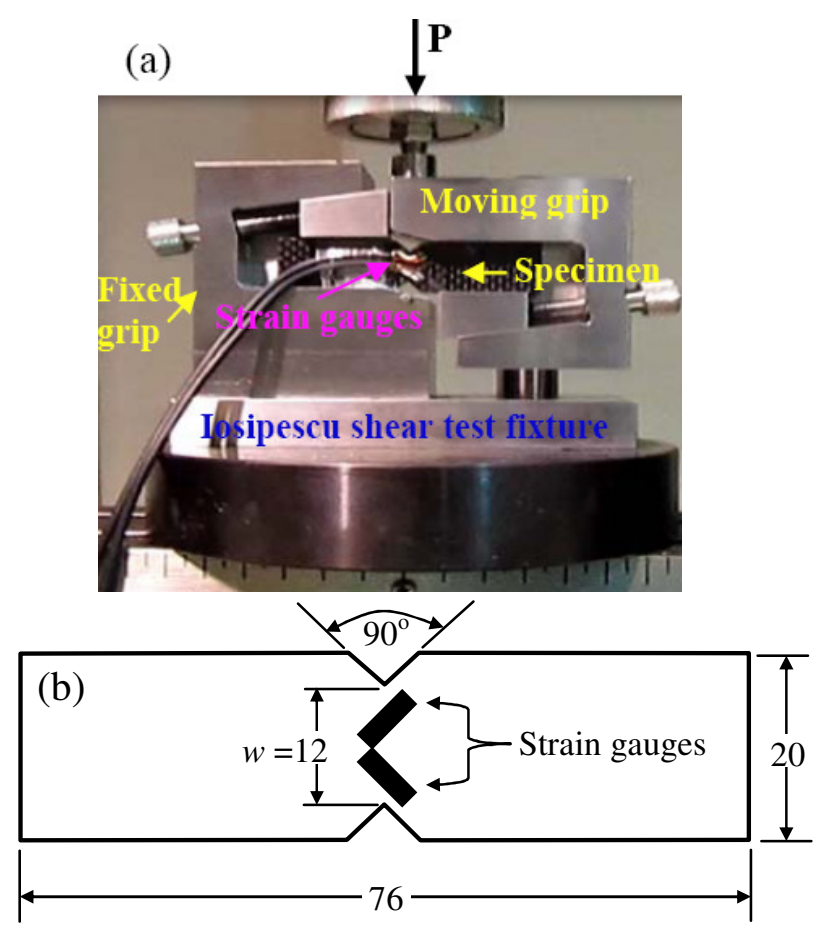

Fig. 2. (a) losipescu shear test fixture, (b) dimensions of in-plane shear specimen, ASTM D5379.

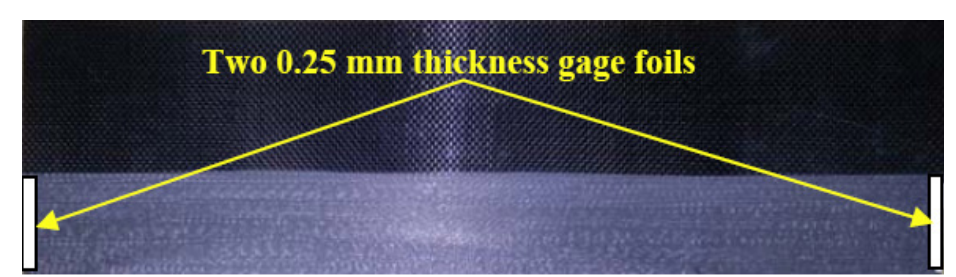

Fig. 3. Two $0.25 \mathrm{~mm}$ gage foils for determining the bond line thickness of the adhesive joints with $5^{\circ}$ scarf angle. 
(a)

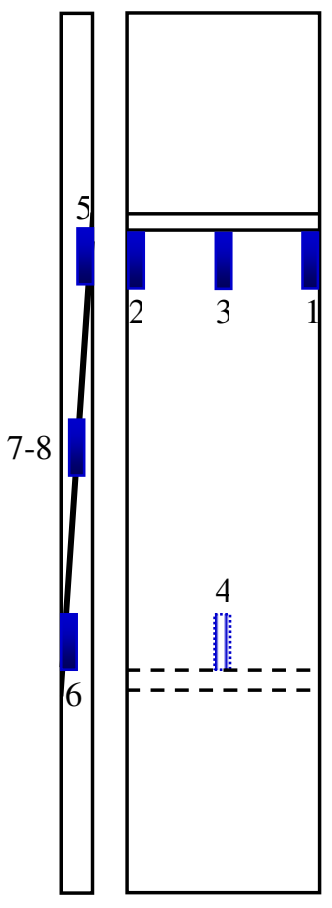

(b)

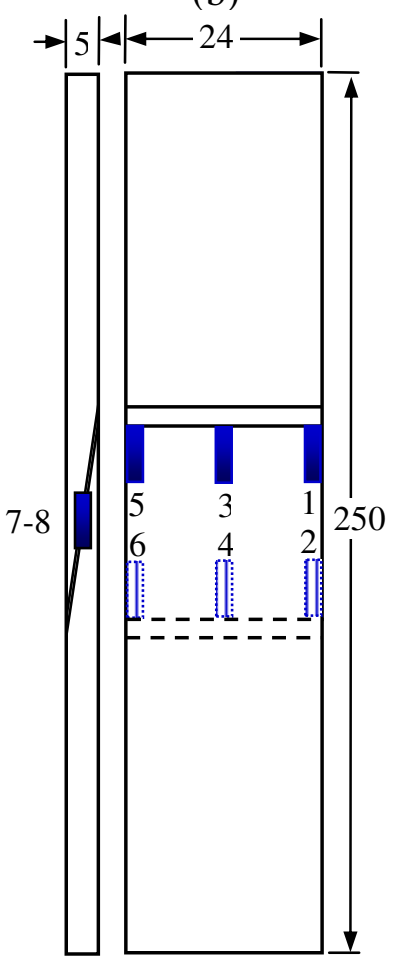

(c)

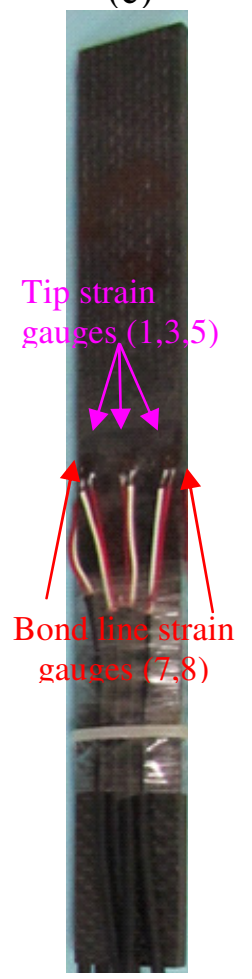

Fig. 4. Dimensions and strain gauge distributions in the structural bonded scarf joints: (a) scarf angle $=5^{\circ}$ (strain gages 7 and 8 are bonded back to back), (b) the other scarf angles $\left(10^{\circ}-\right.$ $45^{\circ}$ ), (c) photograph of instrumented CFRE joint with $10^{\circ}$ scarf angle.

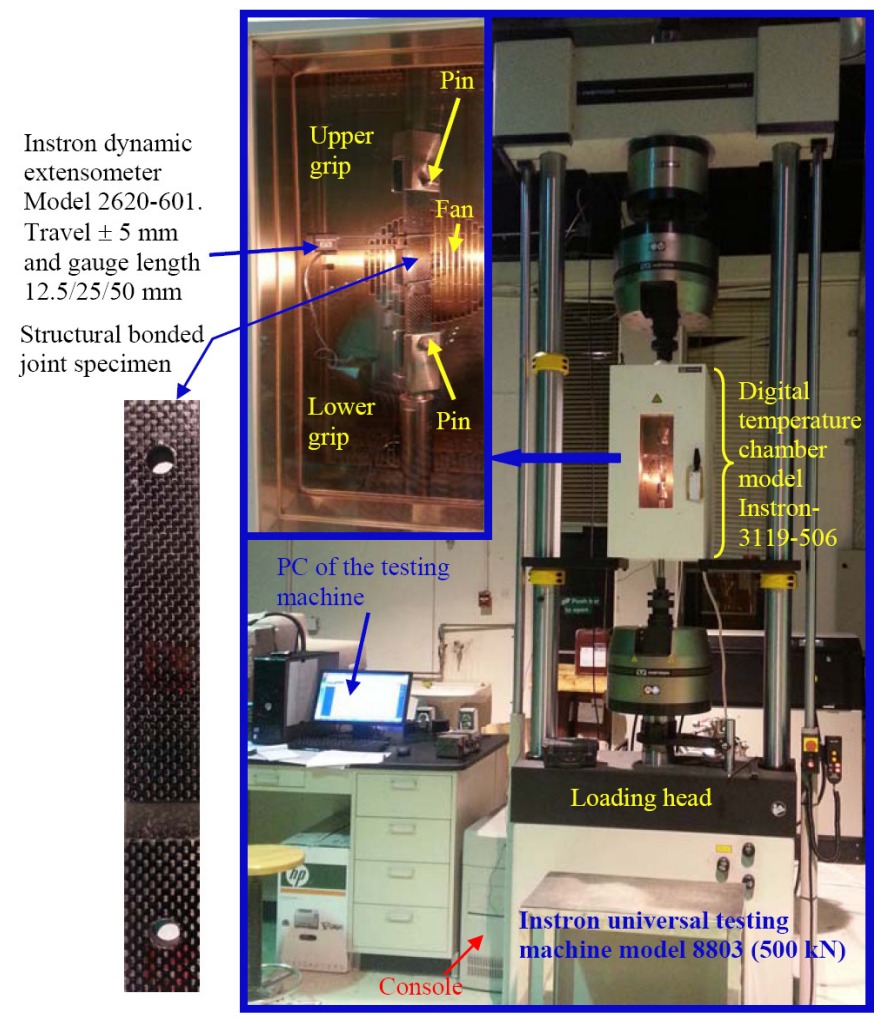

Fig. 5. Experimental setup for testing the structural bonded joint specimen under high temperature. 


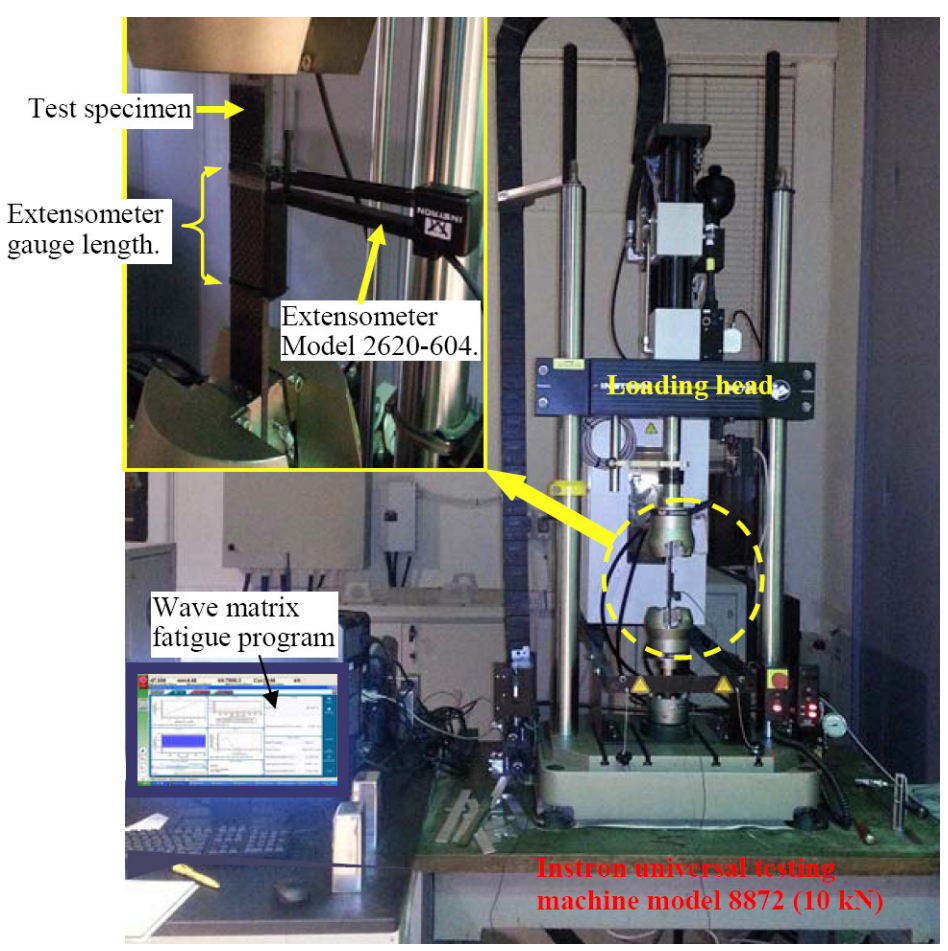

Fig. 6. Experimental setup of Instron servohydraulic universal testing machine model $8872(10 \mathrm{kN})$ for fatigue testing of the structural bonded joint specimens.

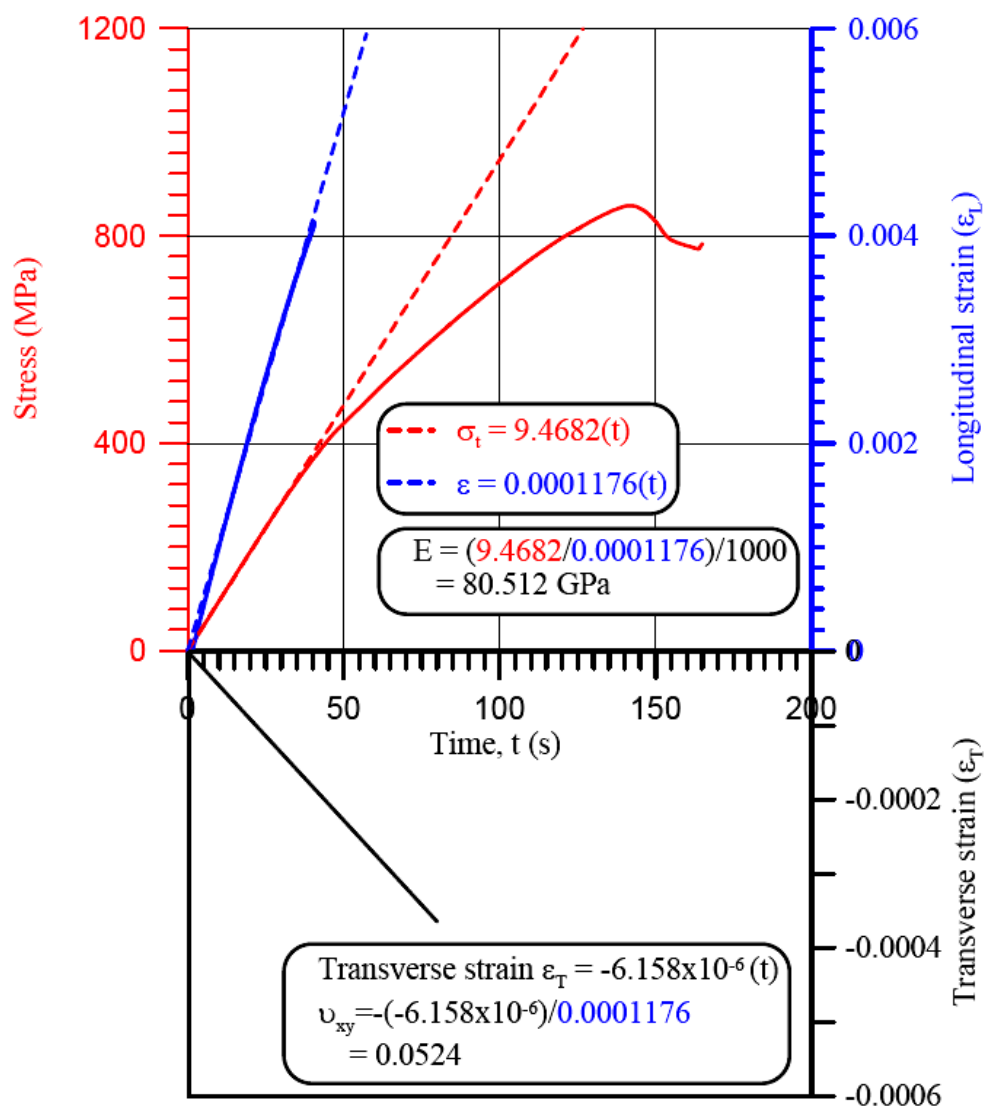

Fig. 7. Stress-time, longitudinal strain-time, and transverse strain-time relationships of CFRE composite adherends in tension. From this figure the ultimate tensile strength, Young's modulus, and Poisson's ratio are calculated. 

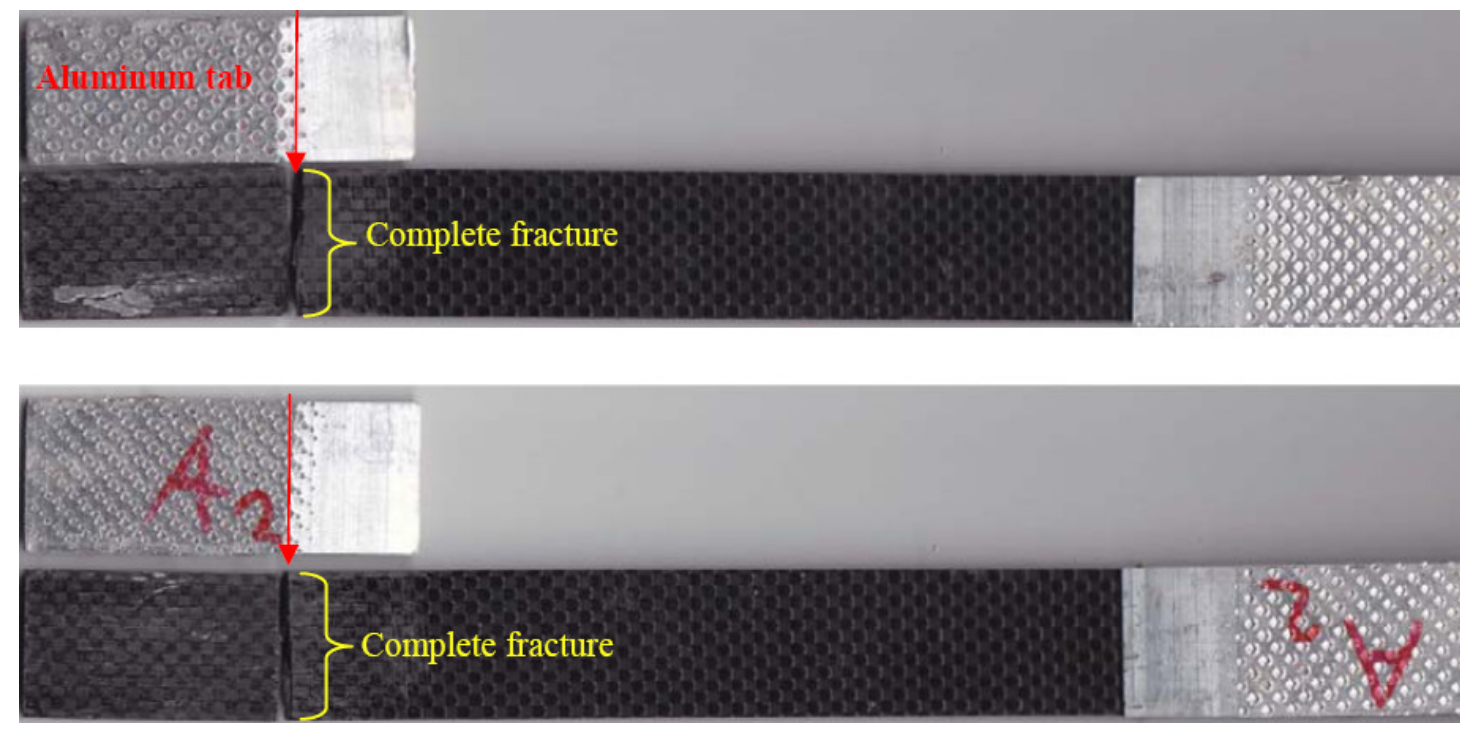

Fig. 8. Photos of some fractured CFRE composite adherends in tension.

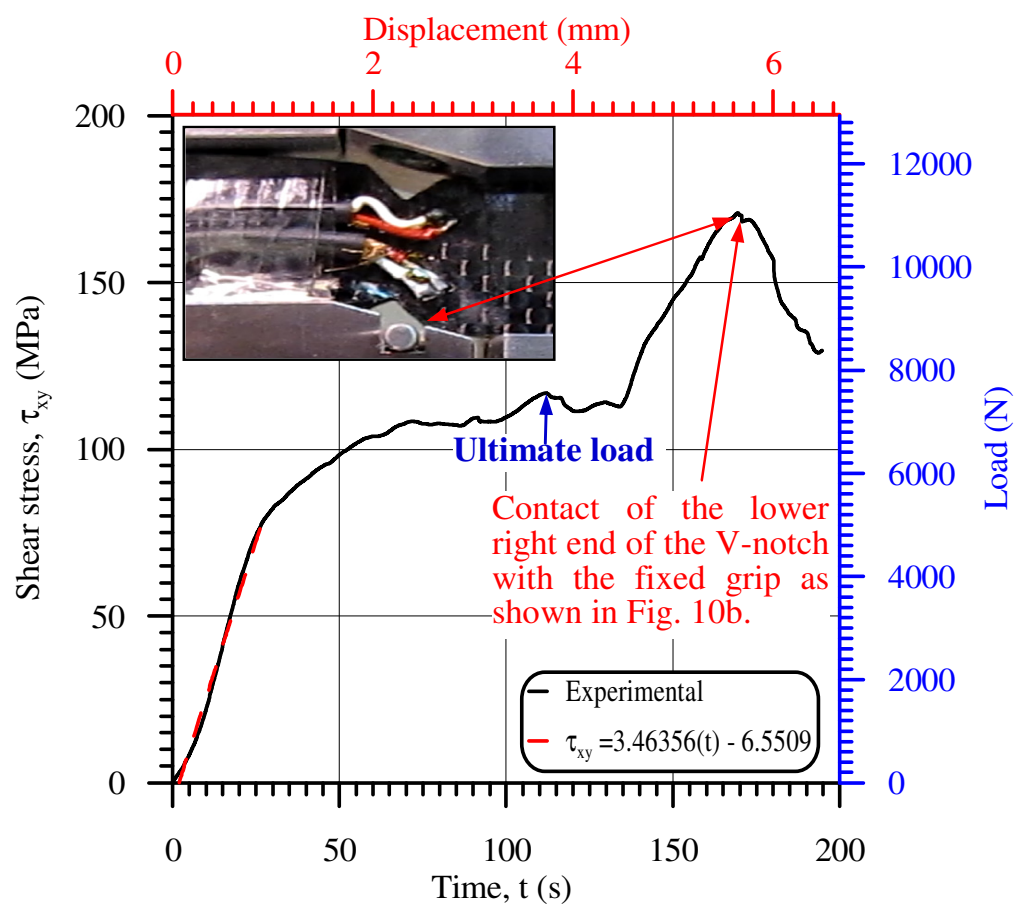

Fig. 9. Shear stress vs time in losipescu shear test of CFRE composite adherends. 

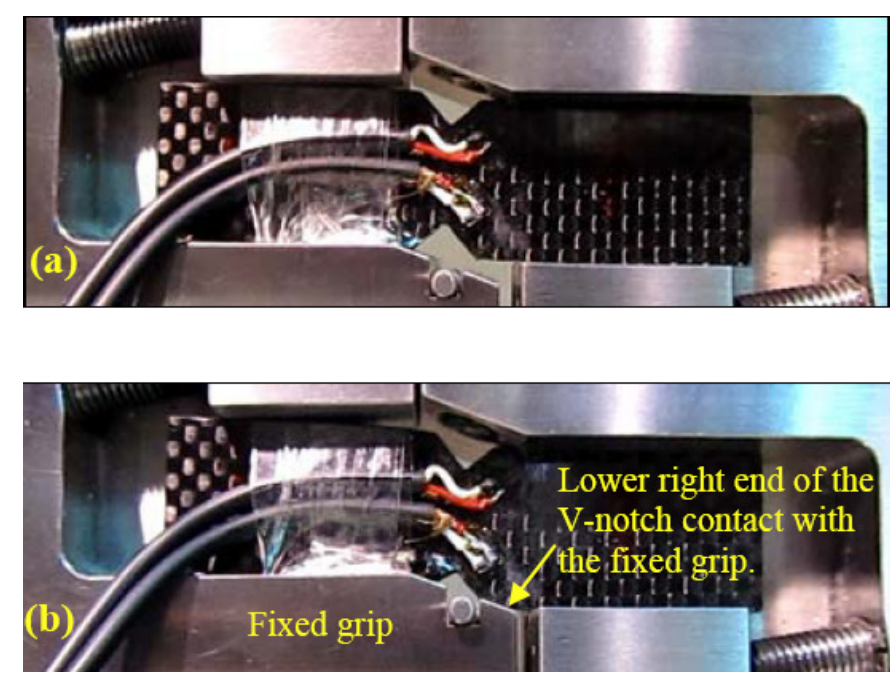

Fig. 10. (a) Photo of CFRE composite adherends at the start of losipescu shear test, (b) photo of fractured specimen losipescu shear test. The specimen is not completely separated as in nanocomposite materials. The shear failure of the specimen was accompanied with evidently drop in the applied load after it reached its ultimate value. The load is further rapidly increased as shown in Fig. 9 due to the contact of the lower right end of the V-notch with the fixed grip, Fig. (a). In such case the test should be stopped.

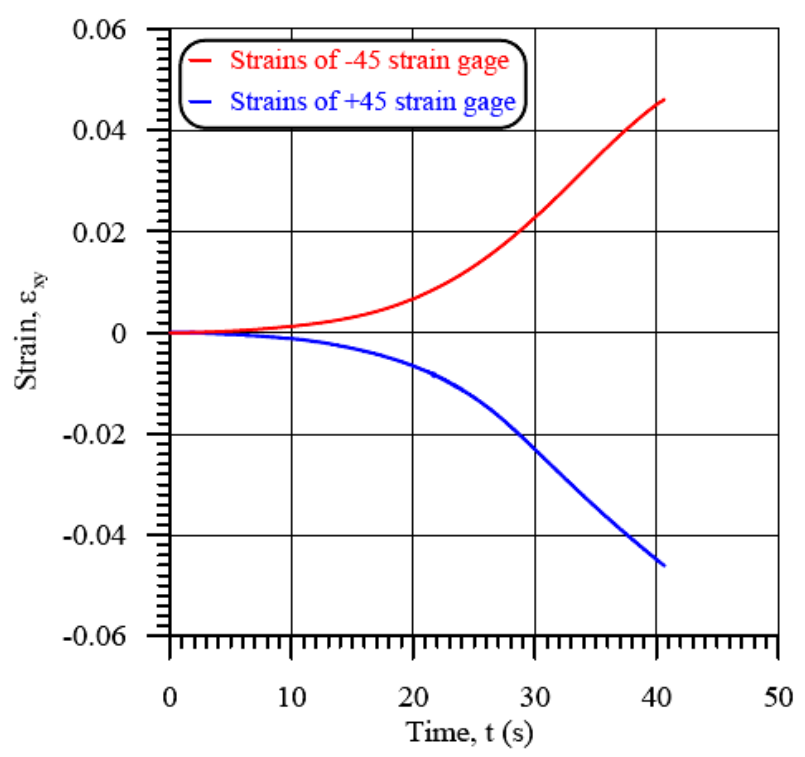

Fig. 11. Strain variation of $\pm 45^{\circ}$ strain gages vs time in losipescu shear test of CFRE composite adherends. 


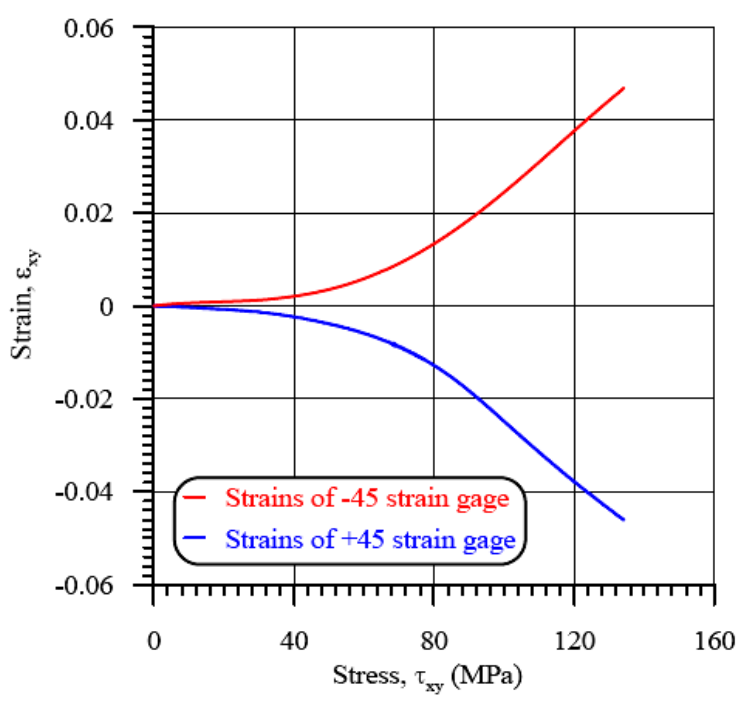

Fig. 12. Strain variation of $\pm 45^{\circ}$ strain gages vs stress in losipescu shear test of CFRE composite adherends

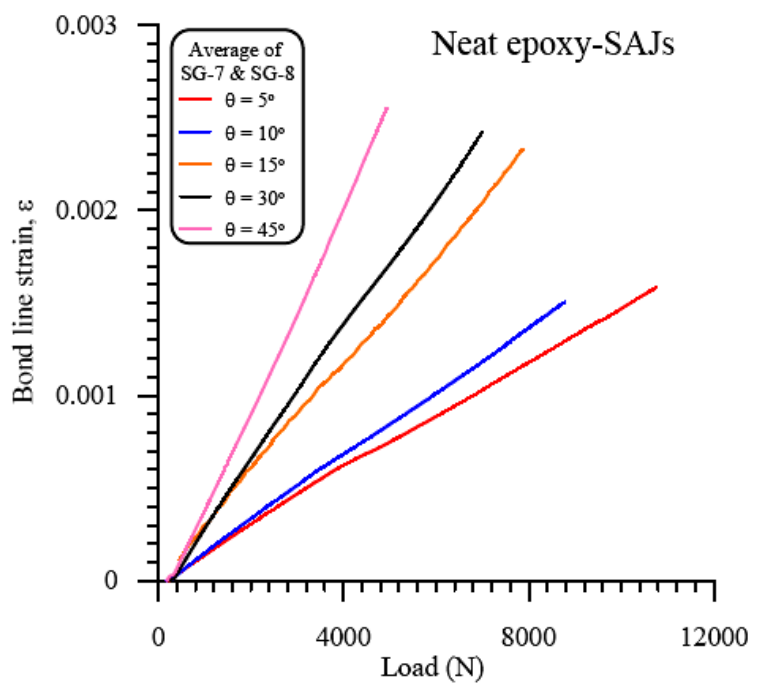

Fig. 14. Bond line strain vs. load for neat epoxy adhesive bonded joints with different scarf angles.

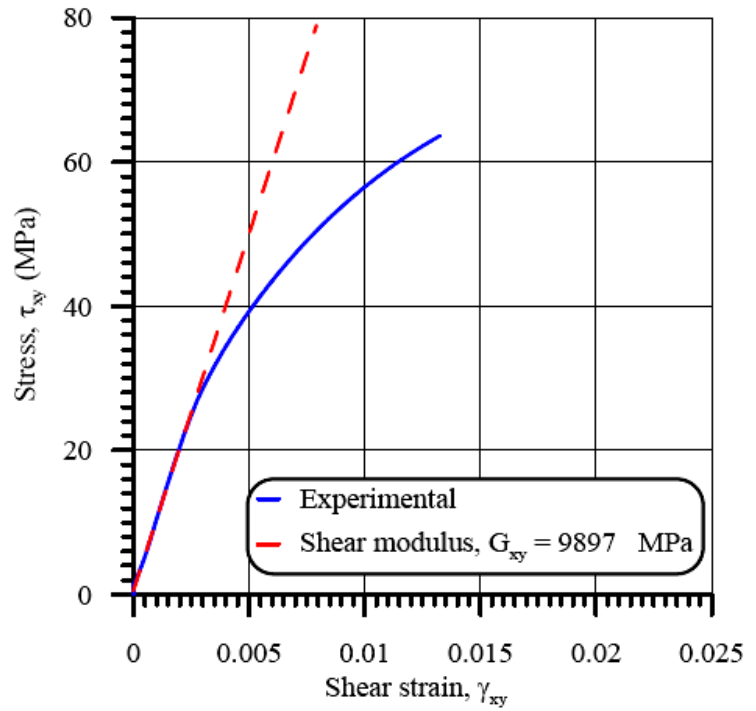

Fig. 13. Variation of shear strain vs shear stress in losipescu shear test of CFRE composite adherends.

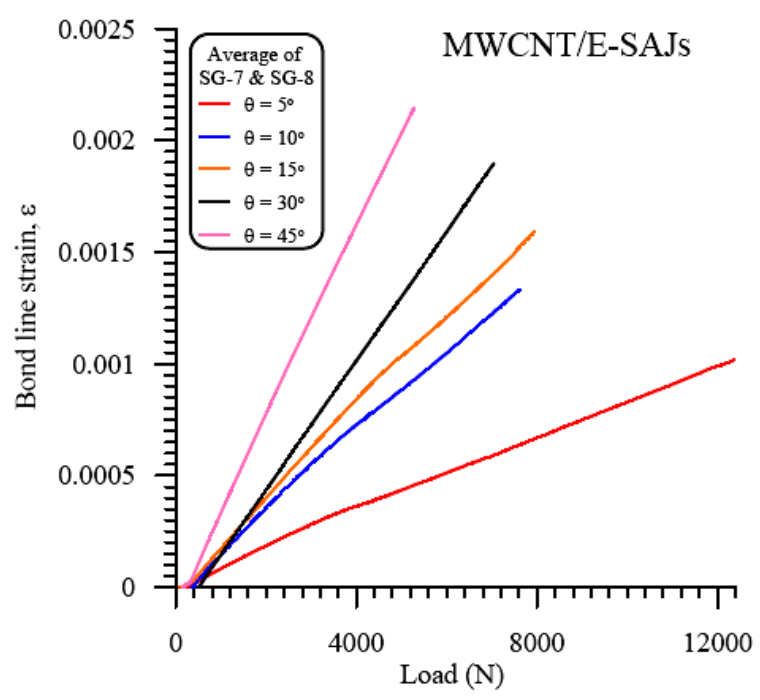

Fig. 15. Bond line strain vs. load for MWCNT/E adhesive bonded joints with different scarf angles. 


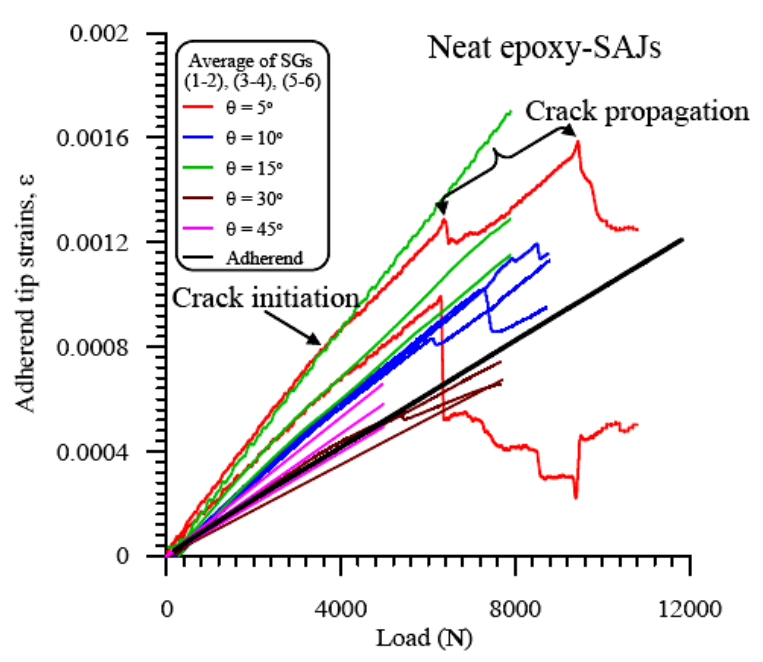

Fig. 16. Adherend tip strain vs. load for neat epoxy-SAJs with different scarf angles.

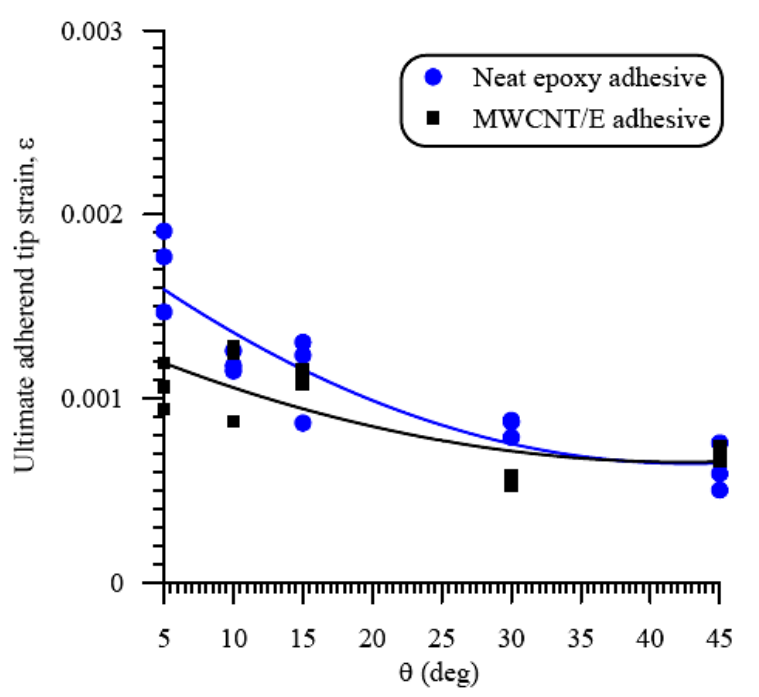

Fig. 18. Ultimate failure adherend tip strain vs. scarf angles for neat epoxy and MWCNT/E adhesives.

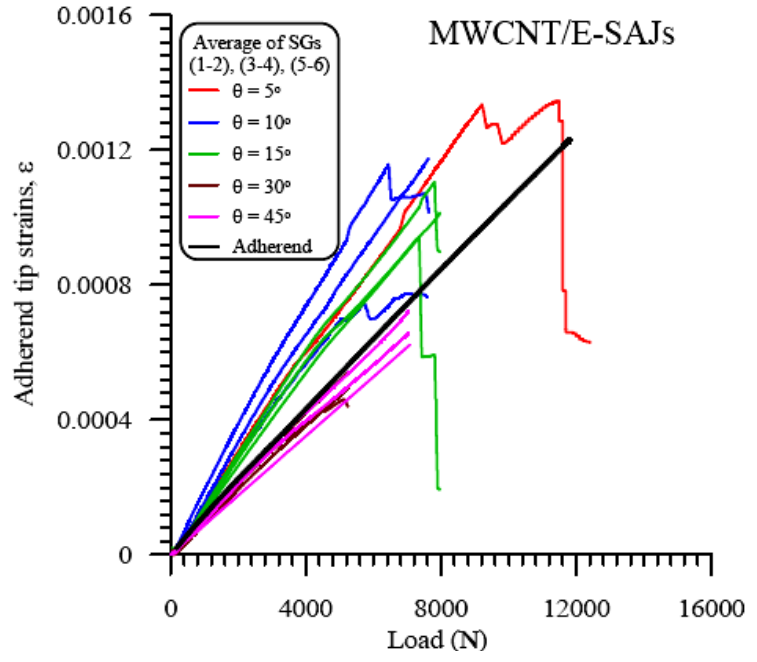

Fig. 17. Adherend tip strain vs. load for MWCNT/E-SAJs with different scarf angles.

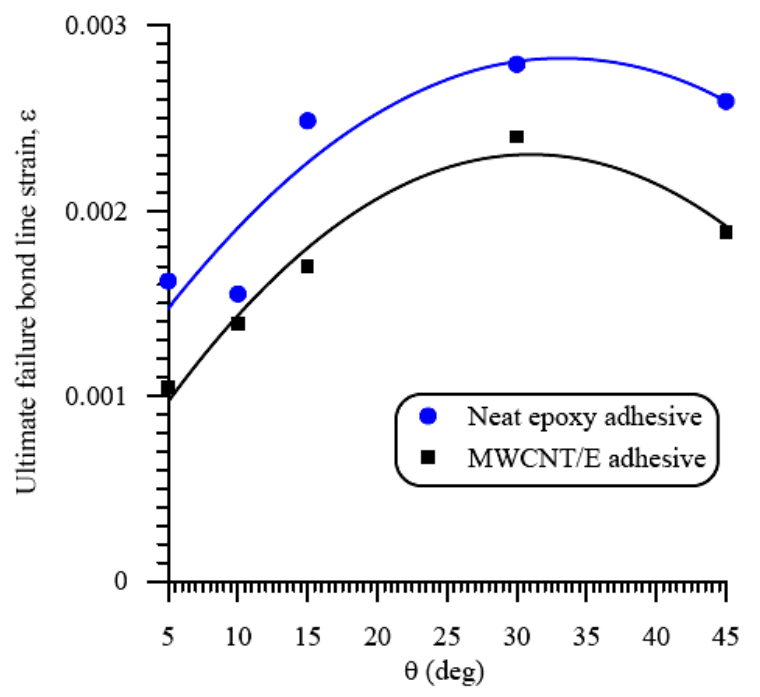

Fig. 19. Ultimate failure bond line strain vs. scarf angles for neat epoxy and MWCNT/E adhesives. 


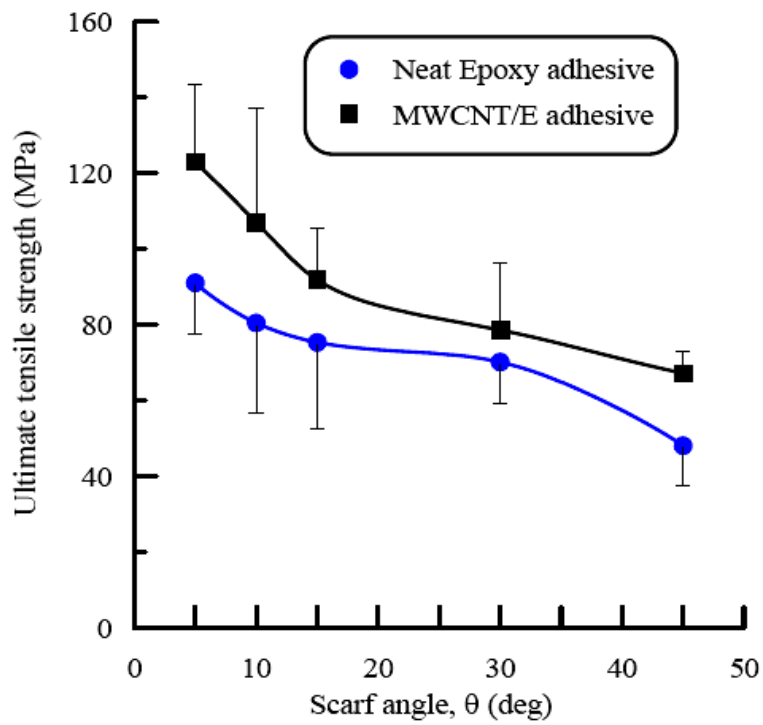

Fig. 20. Ultimate tensile strength vs. scarf angle for neat epoxy and MWCNT/E adhesives.

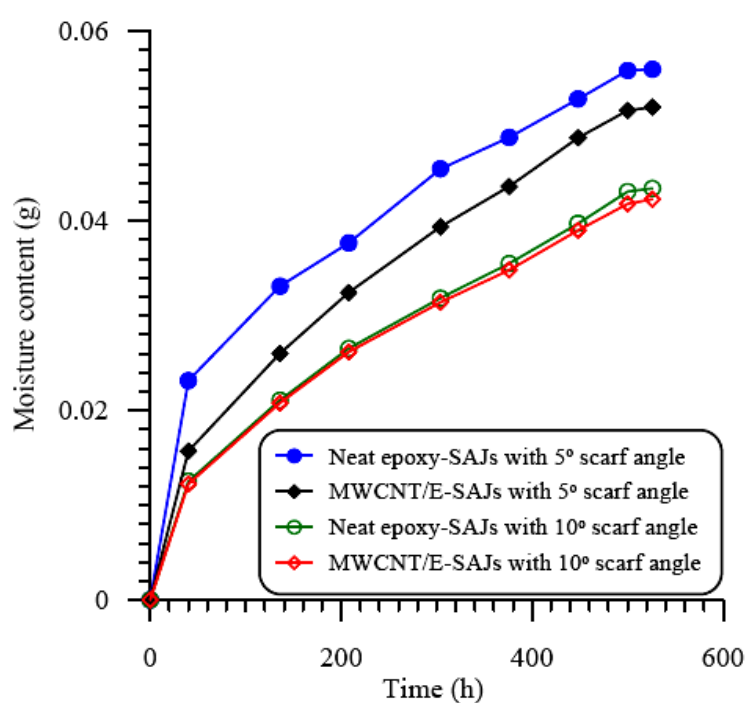

Fig. 22. Moisture content vs. immersion time of SAJs with $5^{\circ}$ and $10^{\circ}$ scarf angles and different adhesives.

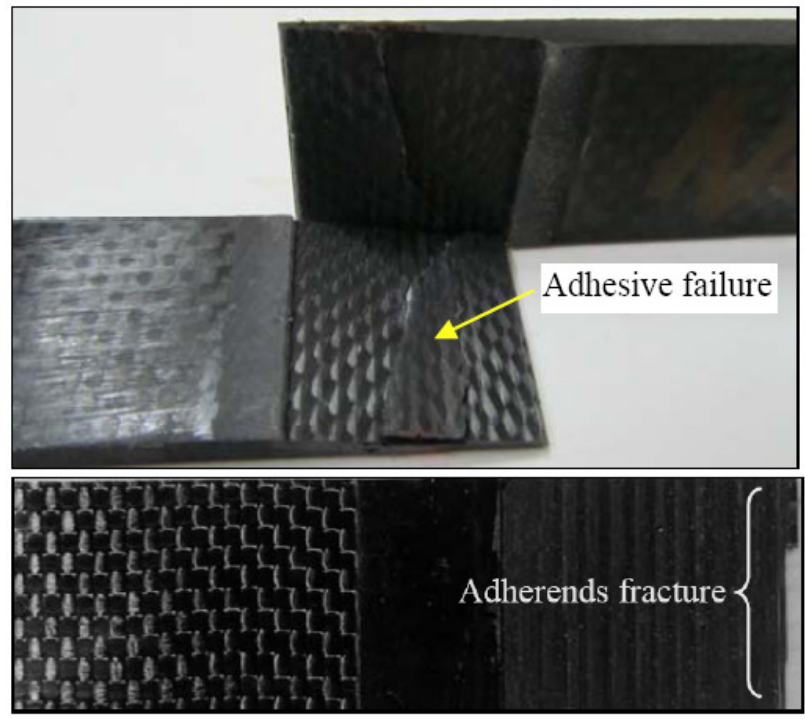

Fig. 21. Photographs of some fractured SAJs specimens

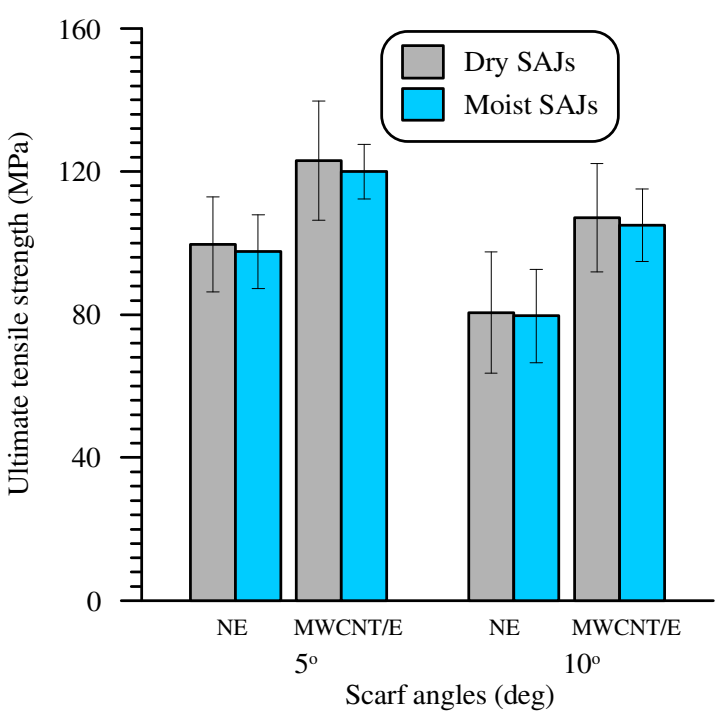

Fig. 23. Comparison between tensile strengths of dry and moist SAJs with $5^{\circ}$ and $10^{\circ}$ scarf angles after $526 \mathrm{~h}$ immersion time. 


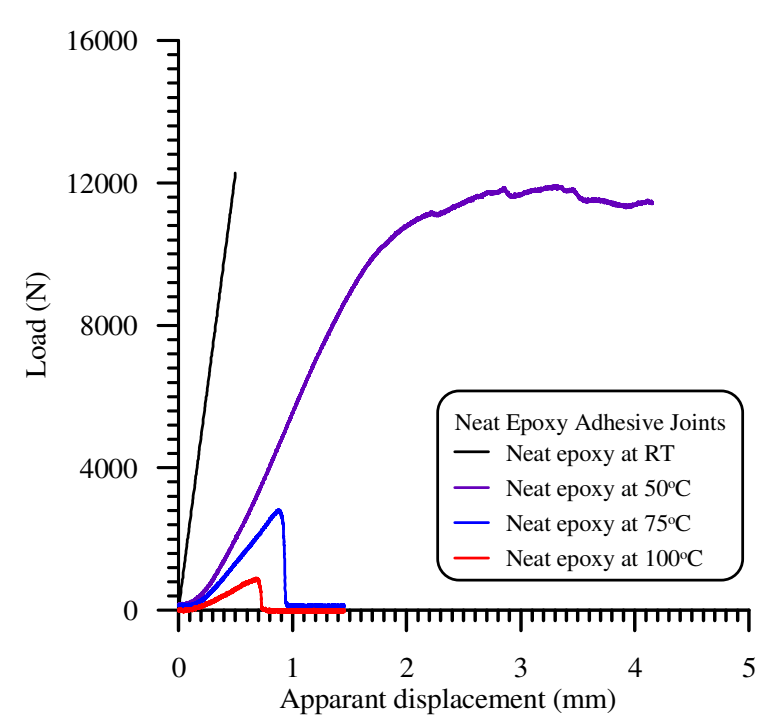

Fig. 24. Load-displacement curves of the structural adhesive joints with neat epoxy adhesives tested in tension under different temperatures.

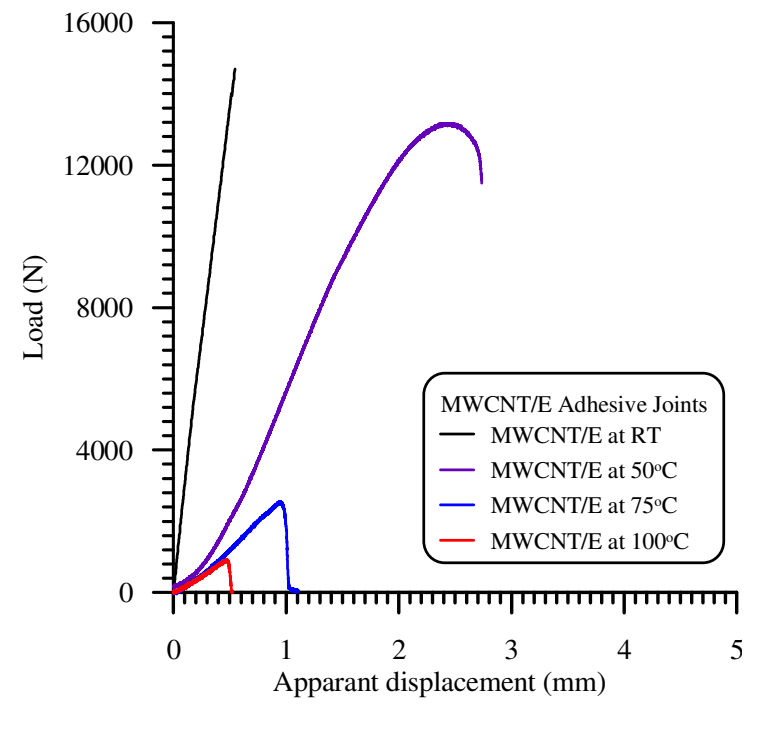

Fig. 25. Load-displacement curves of the structural adhesive joints with MWCNT/E adhesives tested in tension under different temperatures.

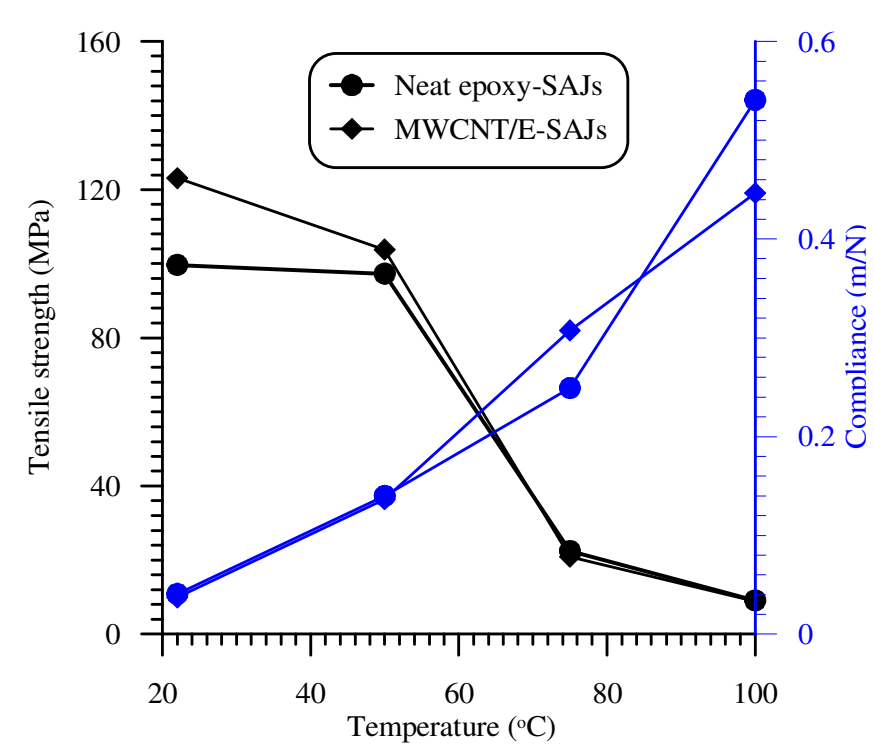

Fig. 26. Tensile strengths and compliances vs. temperature of the neat epoxy and MWCNT/E SAJs

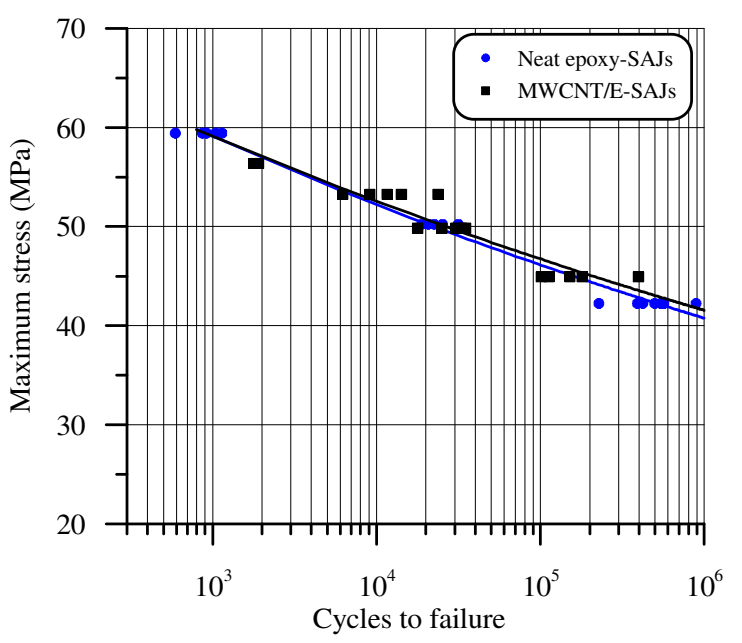

Fig. 27. S-N curves of the neat epoxy and MWCNT/E SAJs with $5^{\circ}$ scarf angle 